Faculdade de Ciências Econômicas UFRGS
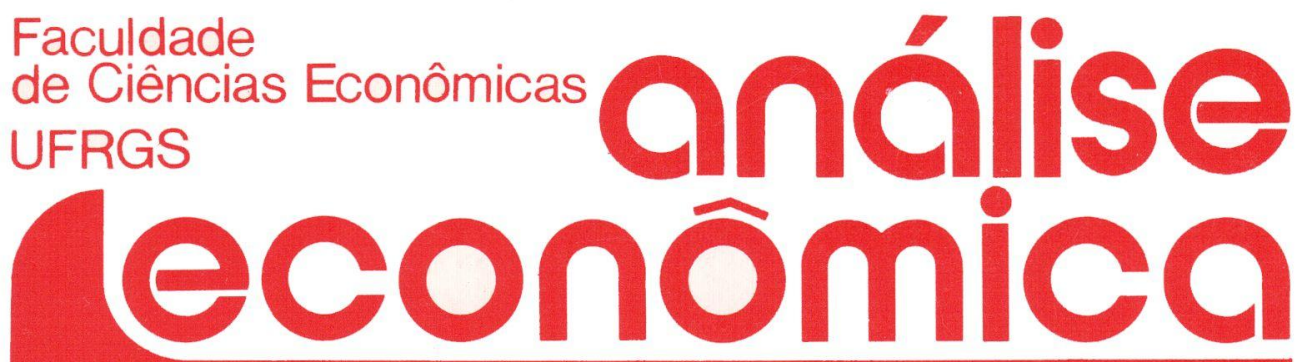

nesta edição:

- PIERO SRAFFA: 1898 - 1983

Nicholas Kaldor

- A BUSCA DOS FUNDAMENTOS, SEM CHOQUES

Yeda Rorato Crusius

- estado e acumulação DO CAPITAL

Paulo Nakatani

- abastecimento

ALIMENTAR

BRASILEIRO

Edgar Irio Simm

- política

RIOGRANDENSE NA REPÚBLICA VELHA

Céli Regina J. Pinto
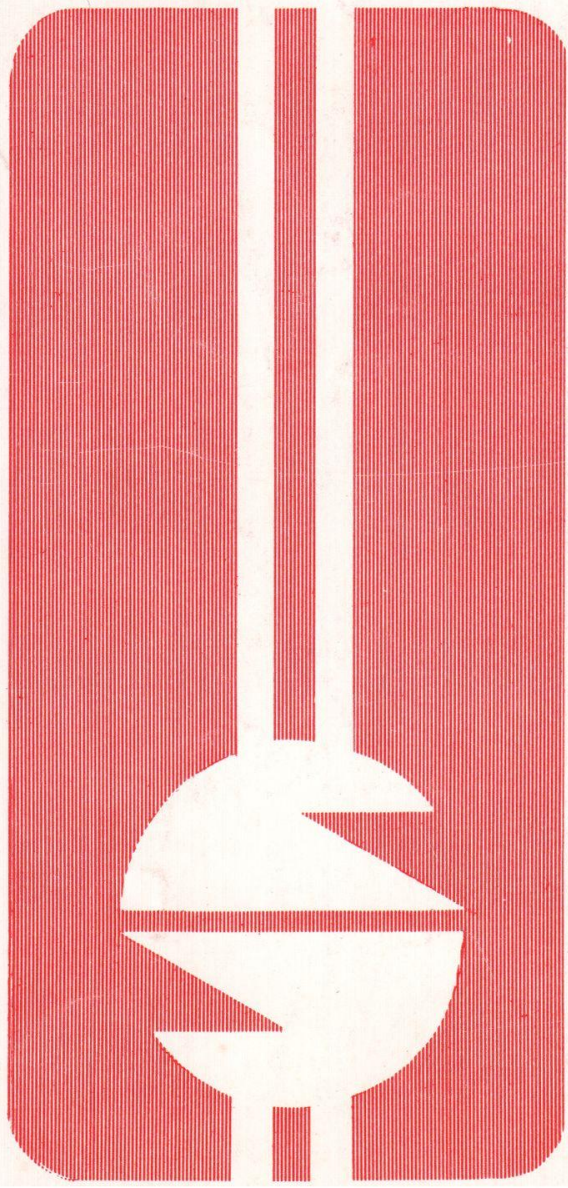
REITOR: Prof. Francisco Ferraz

DIRETOR DA FACULDADE DE CIENCIAS ECONOMICAS:

Prof. Edgar Irio Simm

VICE-DIRETOR: Prof. Walter Meucci Nique

CHEFE DO DEPARTAMENTO DE CIÉNCIAS ECONOMICAS:

Prof. Ernani Hickmann

CONSELHO EDITORIAL:

$$
\begin{aligned}
& \text { Prof. Pedro Cezar Dutra Fonseca (Presidente) } \\
& \text { Prof. Achyles Barcelos da Costa } \\
& \text { Prof. Carlos Augusto Crusius } \\
& \text { Prof. Claudio Francisco Accurso } \\
& \text { Prof. Edgar Augusto Lanzer } \\
& \text { Prof. Ernani Hickmann } \\
& \text { Prof. Juvir Mattuella } \\
& \text { Prof. João Rogério Sanson } \\
& \text { Prof. Maria Imilda da Costa e Silva } \\
& \text { Prof. Nali de Jesus de Souza } \\
& \text { Prof. Nuno Renan L. de Figueiredo Pinto } \\
& \text { Profa Otilia Beatriz Kroeff Carrion } \\
& \text { Profa Yeda Rorato Crusius } \\
& \text { Prof. Paulo Alexandre Sphor } \\
& \text { Prof. Roberto Camps Moraes }
\end{aligned}
$$

FUNDADOR:

$$
\text { Prof. Antonio Carlos Rosa }
$$

ANÁLISE ECONÓMICA publica dois números anuais nos meses de março e novembro. O preço da assinatura para 1987 é $\mathrm{Cz} \$ 60,00$, a ser pago através de cheque nominal para "Faculdade de Ciências Econômicas - UFRGS". Aceita-se permuta com revistas congêneres. Aceitam-se, também, livros para elaboração de resenhas ou recensões.

Toda a correspondência, material para publicação, assinaturas e permutas devem ser dirigidas a:

Prof. PEDRO CEZAR DUTRA FONSECA

Revista Análise Econômica

Av. João Pessoa, 52 - 3. andar

90.000 - Porto Alegre (RS) - Brasil 


\section{ESTADO E ACUMULAÇÃO DO CAPITAL. \\ DISCUSSÃo SOBRE A TEORIA \\ DA DERIVACÁ̃O}

PAULO NAKATANI

\section{I- INTRODUÇĀO}

Dispõe-se, atualmente, de inúmeros trabalhos nos quais se critica a concepção do Estado como algo externo ao capital ou à sociedade civil. Esta, opõe o Estado à sociedade civil ou o Estado ao Capital. Em seus extremos, colocam o Estado como algo acima da sociedade e das classes sociais, como um "deus ex-machina"; ou como simples instrumento da classe dominante Em ambos os casos, o Estado é considerado como neutro, uma casca vazia, cuja natureza varia segundo o conteúdo que nela se introduza. A grosso modo, estas concepções são as da teoria burguesa por um lado, e das instrumentalistas, por outro.

No primeiro caso, o Estado aparece ou é considerado como instituição acima do capital e da sociedade, todo poderoso, portanto, com autonomia total. Esta concepção coloca o Estado acima da lei do valor, a qual pode modificar. Modificar no sentido em que a intervenção estatal seja um instrumento capaz de suprimir as contradições próprias ao capitalismo, sem exigir a eliminação do capital.

No segundo caso, o Estado é considerado instrumento do grupo, classe ou fração de classe no poder. Esta teoria exprime a idéia, na qual o Estado pode ser utilizado segundo os interesses daqueles que detêm seu poder. Na sociedade capitalista contemporânea, o Estado é controlado pelas frações monopolistas do capital. Isto significa que é completamente dominado, submisso a esta parcela do capital; portanto, sem nenhuma autonomia. A formulação principal destas teorizações coloca que o aparelho de

* Professor do Departamento de Economia e Finanças e do Mestrado ern Economia da Universidade Federal da Paraíba, Campus II - Campina Grande.

\begin{tabular}{|l|l|l|l|l|l|} 
ANALISE ECONÓMICA & ANO 5 & N. 8 & MARÇO/87 & p. 35-64
\end{tabular}


Estado é dominado e/ou controlado por indivíduos pertencentes ou em estreita ligação com a fração do capital que se transformou em monopolista. Isto permite a este grupo utilizar o Estado segundo suas necessidades. Enfim, esta concepção implica em que o Estado como um instrumento, serve ao grupo no poder, para realizar seus objetivos de classe; inversamente, o proletariado poderia, em se apossando deste aparelho, dirigi-lo para a realização de seus objetivos de classe ${ }^{(1)}$.

A crítica a estas concepções leva-nos à proposição na qual a relação Estado/capital deve ser orgânica. Isto quer dizer que não existe "separação" entre o Estado e o capital; que as relações en. tre eles não são somente relações de exterioridade.

Uma destas correntes ${ }^{(2)}$, em oposição às análises baseadas no conteúdo do Estado, fundamenta-se no estudo da FORMA ESTADO. Esta análise deduz (deriva) a Forma Estado das contradições da dinâmica do capital, na qual, a natureza desta relação confere ao Estado sua natureza capitalista.

\section{II - A ESCOLA DA DERIVAÇĀO: ALGUMAS CONTRIBUIÇŐES}

A teoria da derivação ${ }^{(3)}$ não constitui, exatamente, um conjunto teórico acabado. Apresenta-se sob forma de debate, no qual aparece uma série de contribuições, dentre as quais escolhemos algumas como base de nosso estudo.

Holloway \& Picciotto (1980: p.36) consideram que “. . . podemos distinguir duas orientações gerais - ou talvez três - que não se constituem, entretanto, em posiçôes definitivas".

A primeira deriva ". . . a necessidade da forma Estado como instituição separada, a partir das relações entre os capitais individuais (p.36)" ; a segunda insiste ". . . sobre a necessidade de fundamentar a análise do Estado sobre as formas de aparição das relações capitalistas na superfície da sociedade e, não sobre a natureza essencial do capital (p.41)"; e a terceira, "... sustenta que a forma particular do Estado deve ser derivada não da necessidade de estabelecer o interesse geral em uma sociedade anárquica, mas da natureza das relações sociais de dominação da sociedade capitalista (p.43)".

Não pretendemos seguir estudando cada uma destas orientações; preferimos realizar o estudo de alguns textos e, tentar extrair deles o procedimento exato de derivação do Estado. A escolha dos textos foi arbitrária, em função de sua disponibili- 
dade, mas não menos significativa. Desta maneira tomamos como ponto de partida os textos dos seguintes autores: Elmar Altvater, Margaret Wirth, Joachim Hirsch e Pierre Salama ${ }^{(4)}$.

\section{Elmar Altvater}

Este autor parte da distinção entre capital em geral e capitais individuais (que ele chama de múltiplas unidades de capital): O capital em geral tem existência real como o capital social total (5). Neste nivel, não se consideram as condições concretas de sua existência, como a concorrência entre os capitais e o sistema de crédito. A manifestação concreta do capital em geral, apresen ta-se sob forma de múltiplas unidades; são os capitais individuais.

Esta distinção permite separar aquilo que poder íamos chamar de "interesse do capital em geral" e "os interesses das unidades de capital". A realização dos interesses das unidades de capital reflete-se por "suas interações, as condições médias de exploração, mesma taxa de mais valia, mesma taxa de lucromédio (Altvater, 1975. p. 137)"; entretanto, esta realização apresenta-se como contraditória à reprodução do capital em geral.

Altvater (p.137) considera que, "naturalmente é ao nível do conceito de capital em geral que se manifesta a forma na qual as leis gerais (como tendências) do Modo de Produção Capitalista se realizam, fora e em reação às operações das unidades de capital. Esta forma é a concorrência, na qual se revelam as leis imanentes e inexoráveis da produção capitalista. A concorrência não é, entretanto, o aspecto principal" . Para ele, o principal é a existência de atividades que não podem ser realizadas pelas unidades de capital. Exprime estas idéias nos seguintes termos: "ou bem a produção de certas condições materiais de produção não produzem lucros, ou bem certas regulações estão em condições dadas muito gerais para que possam ser realizadas pelas unidades de capital, limitadas por seus interesses particulares (p.137)"..

Desta maneira, é a existência de um tipo de atividade (que não pode ser executada por uma unidade de capital) que torna o Estado necessário. Assim o Estado é uma instituição especial que escapa às restrições de reprodução, às quais estão submetidos os capitais individuais.

Em outros termos, a realização dos interesses de cada unidade de capital, torna-se contraditório à realização do interesse do capital em geral. E por esta razão que os Estado torna-se necessário, pois "exprime interesse geral do capital (p.138)". Mas isto não 
implica na eliminação da "anarquia do mercado (...) o Estado não se substitui à concorrência"; mas assegura "as bases fundamentais de existência da classe operária, enquanto objeto de exploração, cria as condições gerais da produção e, inclusive, as relações jurídicas. Contrariamente ao capital que, por ele mesmo, é incapaz de produzir estes fundamentos (p.139)"

Podemos resumir suas idéias da seguinte maneira:

1 . - a contradição entre a reprodução dos capitais individuais e a reprodução do capital em geral, exige a produção de certas condições gerais para a reprodução do capital;

$2^{\circ}$. - a produção destas condições gerais não pode ser realizada pelos capitais individuais pressionados pela caça ao lucro;

3. - é necessário uma instituição especial capaz de produzir estas condições gerais e que não esteja submetida às mesmas restrições;

4? - esta instituição é o Estado, que, para realizar as condições gerais, deve ser independente da sociedade burguesa e superior a ela.

Mais precisamente, Altvater sublinha que é sobre a "criação das condições gerais de produção" que repousa a autonomia do Estado.

Vejamos, agora, o que é que ele considera como condições gerais de produção. Quando ele define as funções do Estado, afirma que "Os processos produtivos indispensáveis assumidos ou ao menos controlados pelo Estado, devem crescer como conseqüência da tendência histórica à queda na taxa de lucro. Ela tèm como conseqüência que, de mais a mais, processos de produção tornamse não rentáveis e serão abandonados ou reduzidos pelos capitais individuais, quase desaparecendo da esfera do capital concorrencial (p.141, sublinhado pelo autor)".

Na segunda seção de seu artigo, desenvolve o conceito de condições gerais. Para ele, são as atividades não rentáveis para os capitais individuais privados; mas não chega a demonstrar porque são necessárias à reprodução do capital em geral. Parece-nos que fica a idéia implícita de que estas atividades são necessárias pelo fato de sua existência concreta ${ }^{(6)}$

Entretanto, tenta demonstrar que estas atividades não são rentáveis para os capitais privados, demonstração que é bastante contestável. Cita, por exemplo, a massa de investimentos necessários e o período de maturação desta capital; a produção, cujo resulțado não apresenta o caráter de um bem imediato (qualificação, resultados de pesquisas); a estreiteza dos mercados, etc. Contra es- 
tes argumentos, pode-se opor o fato de que as atividades que ele considera não rentáveis, são-no atualmente, mas nem sempre o foram; são nada mais do que o resultado do movimento hiștórico do capital.

Por outro lado, distingue a produção da operação dos meios de produção. A produção pode ser rentável mas a operação não. Utiliza como exemplo a construção de pontes e sua operação; outro exemplo é o da construção de escolas e o ensino. A construção ou a produção é rentável, mas a operação não é rentável. A construção é realiz̧ada pelos capitais privados; a operação pelo Estado.

Nós achamos esta análise restritiva e a-histórica. É restritiva, porque a produção não é rentável para os capitais privados em certas condições; e tudo que é necessário ao capital pode vir a ser rentável. Por outro lado, a não rentabilidade da operação pode ser também ilusória. Dentro do atual campo de atividades do Estado, pode-se encontrar atividades tão rentáveis quanto algumas atividades privadas.

Ela é a-histórica porque não leva em conta o movimento de transformação das atividades capitalistas. Fundamentar a necessidade do Estado sobre a não rentabilidade atual das ferrovias, não explica o Estado quando o setor ferroviário era um dos mais rentáveis. Isto quer dizer que dentro do Modo de Produção Capitalista encontraremos sempre atividades rentáveis e não rentáveis, definidas espacial e historicamente. A definição da rentabilidade ou não é fruto das contradições internas ao processo de reprodução do capital.

Visto puramente sob este aspecto, o resultado será o movimento dos capitais entre diferentes ramos e setores ou mesmo entre diferentes atividades. $\bar{E}$ a associção entre a não rentabilidade e a necessidade para o capital sob restrição da impossibilidade de vir a ser rentável que fundamentaria o Estado. Mas este procedimento não é realizado pelo autor.

\section{Margareth Wirth}

Wirth toma como ponto de partida cuja crítica à teoria do Capitalismo Monopolista de Estado. Opondo-se a esta teoria Wirth propõe que :'a constituição formal da liberdade e igualdade entre todos (...) é a forma estatal adequada ao capitalismo desenvolvido (p.114)".

Fundamenta seu estudo respondendo às questões seguintes 
1 - "por que a liberdade e igualdade de todos enquanto possuidores de mercadorias é uma condição prévia necessária à reprodução do capital"; 2 -- por que "esta liberdade e esta igualdade formais devem ser protegidas por um poder organizado, externo aos capitais, tanto contra àqueles que querem transformá-lo em uma liberdade e uma igualdade reais quanto contra àqueles que querem destruir a igualdade e liberdade mesmo formais"; 3 - por que "a contradição entre liberdade e igualdade formais de todos os membros da sociedade, de um lado; e a relação de classe do capital e do trabalho, de outro lado, constituem o limite estrutural das possibilidades de intervenção do Estado no processo de produção (p. 115)".

As respostas a estas questões não são claramente apresentadas. Supomos, então, que o desenvolvimento da afirmação seguinte constitui, também, uma resposta às questões acima. Wirth afirma que: "o Estado enquanto potência extra-econômica e enquanto Estado de classe deve ser deduzido do capital (p.115)" :

Começa observando que aquilo que especifica o Estado capitalista não é o fato de ser um Estado de classe; “o Estado (...) enquanto instrumento de dominação de uma classe sobre outra, não é específico ao capitalismo (p. 115)" ${ }^{\prime \prime}$. Em seguida, a análise da reprodução social através da troca e da produção, permite-lhe destacar os aspectos seguintes: 1 - o capital "libera" o trabalhador dos meios de produção e o torna livre para escolher seu trabalho e seus produtos de consumo; 2 - esta liberdade possibilita que todos os membros da sociedade tornem-se compradores e vendedores: 3 - mas, a liberação dos trabalhadores faz com que o trabalho (a força de trabalho) venha a ser uma mercadoria cujos compradores e vendedores se constituem em classes distintas; 4 - assim, "somente a troca entre as classes, garante o processo global de reprodução (p.117)".

Esta troca entre as classes toma o aspecto de troca entre indivíduos livres e iguais cuja permuta de equivalentes esconde uma transação desigual, que é a exploração da força de trabaIho. O primeiro aspecto se refere à circulação, ao mercado; o segundo, refere-se à produção. Associado ao primeiro aspecto encontramos uma liberdade formal; ao segundo, uma nãoliberdade real. O desenvolvimento "normal" desta contradição é uma solução por si mesma, o que implica, de imediato, na supressão da relação fundamental da sociedade capitalista: o capital.

Para garantir a reprodução desta contradição uma instituição especial é, então necessária. Esta instituição é o Estado que, pela 
violência (seja contra os trabalhadores, seja contra os capitalistas individuais) garante esta reprodução. "O Estado, então, se transforma, tendo sido um meio de manter a dominação de uma classe sobre a outra, em um meio de manter a dominação do capital sobre a sociedade (p.119)".

Para resumir este ponto de vista, podemos dizer que ao contrário de Altvater que deduz o Estado da necessidade de produzir certos valores de uso não-rentáveis para o capital, Wirth deduz - Estado, a partir da contradição entre o Capital e o Trabalho.

Assim, $1^{\circ}$ :- a contradição capital/trabalho se apresenta ao nível da circulação como intercâmbio equivalente; 2 . - esta contradição, ao nivel da produção se transforma em intercâmbio desigual; $3^{\circ}$ :- a contradição entre a liberdade formal e a não liberdade real, formulada por Wirth, tende a se resolver por si mesma; $4^{\circ}$ :- portanto, o Estado é necessário para garantir a reprodução desta contradição.

O que não é evidente é a solução da contradição por si mesma. O raciocínio de Wirth é aparentemente correto. Podemos mesmo aceitá-lo ao nivel de abstração formulado, como um desenvolvimento lógico das contradições. $O$ fato mesmo de que, na realidade, tudo se passa como intercâmbio de equivalentes, entre parceiros livres, independentes e iguais, esconde o intercâmbio desigual, disfarçado por trás destas relações aparentes e, torna duvidoso supor a solução au tomática desta contradição sem a intervenção do Estado (7).

\section{Joachim Hirsch}

Este autor propõe que o Estado "deve ser deduzido em sua forma e seu modo de funcionamento, a partir da análise do processo de reprodução social e de suas leis (p.31)" :Assim, procede a uma análise do processo de reprodução do capital e de suas leis, fundamento da sociedade capitalista.

Seu ponto de partida é a liberdade do trabalhador e do capitalista como pré-condição ao intercâmbio, que, sob a aparência de igualdade, esconde a desigualdade, a exploração da força de trabalho. Por outro lado, a reprodução social sob esta base, "regulada pela lei do valor (...) produz e reproduz continuamente suas próprias condições sociais, sem que exista necessidade de intervenção externa (p.37)"'. Entretanto, o processo de acumulação não deve ser entendido como processo "equilibrado", mas contraditório, "cujas conseqüências culminam na queda tendencial da taxa de lucro (p.38)". 
A análise do funcionamento desta lei, leva-o a afirmar que: "a verdadeira barreira à produção capitalista, é o capital em si mesmo (Marx, citado por Hirsch)" e, "após haver realizado esta dedução da tendência às crises e ao desmoronamento do sistema capitalista como resultante das implicações da lei do valor em si mesma, resta examinar, em particular, a questão de saber por que este desmoronamento não aconteceu até hoje (p.43)".

A resposta a esta questão leva-nos primeiro às referências sobre as contra-tendências à tendência à queda na taxa de lucro. Para Hirsch, não é suficiente referir-se às contra-tendências, mas é ncessário examinar o "desenrolar concreto do processo de acumulação, da concorrência entre os capitais individuais e da crise, através das quais, as leis que indicamos da teoria do valor se manifestam efetivamente sob sua forma contraditória (p.46)" A partir daí, analisa a crise e a função da crise. Esta "não consiste somente em eliminar as desproporcionalidades existentes no aparelho de produção; é, ao mesmo tempo, e sobretudo, um meio através do qual as contra-tendências à queda na taxa de lucro são efetivamente mobilizadas (p.48)". Em outros termos, a crise joga um papel de reorganizador das condiçõ̉es gerais de produção. "O curso real do processo de desenvolvimento e da acumulação na sociedade capitalista, necessariamente carregado de crises, depende, assim, de forma decisiva do sucesso da reorganização necessária das condições de produção e das relações de exploração, e, pela maneira como se processa o sucesso desta organização $(p .49)^{\prime \prime}$. Enfim, apresenta uma re-interpretação (8) de como funciona a lei da tendência à queda na taxa de lucro, que só aparece, em princípio, através das contra-tendências. Esta lei, "descreve os fundamentos objetivos das lutas efetivas de classes. (...) Dos resultados destas estratégias (as ações das classes em luta) e das saídas destas lutas, depende o fato que a lei da tendência à queda na taxa de lucro, seja empiricamente visível ou não. (...) A lei da tendência à queda na taxa de lucro formula a coerência das relações objetivas do desenrolar histórico dos afrontamentos de classes; os fatores que atuam em sentido inverso descrevem os resultados e as condições que tomam a forma de relações sociais complexas (p.50) ":

Assim, a evolução da sociedade capitalista e a necessidade do Estado, não podem ser apreendidas, senão pela análise do desenrolar histórico das leis fundamentais que regem o funcionamento da sociedade capitalista. Este desenrolar contraditório, semeado de crises, não pode existir sem contínua "reorganização das condições gerais de produção". Hirsch analisa estas condições, ou tenta 
precisá-las, sob três formas as modificações de forma do capital: a expansão do capital sobre o mercado mundial; e a aceleração do progresso técnico e científico. Paradoxalmente, estas condições gerais de reprodução do capital, fazem com que os limites à acumulação tornem-se cada vez mais próximos. Examinemos estes aspectos mais de perto.

As modificações de forma do capital consistem na monopolização, na modificação das relações de propriedade e de direção, e na edificação do sistema de crédito. Os dois últimos se constituem muito mais em alavanca à centralização dos capitais sob a forma monopolista, pois "permitem o desenvolvimento das forças produtivas, além dos limites que são colocados pela propriedade privada imediata dos meios de produção (p.52)". A monopolização funciona como "mecanismo de reorganização da estrutura do capital", que permite um desenvolvimento das for ças produtivas além da possibilidade das unidades de capital não monopolistas, permitindo, também, aos monopólios obterem uma taxa de lucro mais elevada. Entretanto, estas vantagens são contraditórias nelas mesmas, pois "agravam as "contradições" que se manifestam na perturbação do processo de reprodução equilibrada do sistema em seu conjunto (p.53)".

Do mesmo modo, as vantagens da expansão mundial são contrabalançadas pelas desvantagens ou pelo aguçamento das contradições. "A capitalização progressiva do mundo e a constituição do mercado mundial (...) significam ao mesmo tempo, generalização das crises e agressividade crescente dos países capitalistas avançados, na luta pelo controle das matérias-primas, dos mercados e das diferentes esferas de investimentos (p.55)" :

Enfim, "com o progresso da ciência e da tecnologia, agravamse (...) as contradições imanentes ao desenvolvimento capitalista das forças produtivas (p.58)". E, a "extensão da ciência à produção, que torna-se historicamente determinante com a progressão do processo capitalista de acumulação e pelas crises, é uma forma na qual se realizam as reações à queda na taxa de lucro, e ativa, ao mesmo tempo, as contradições internas deste modo de produção, engendrando, progressivamente, seu limite absoluto (p.59)" .

Toda a análise da reprodução social, feita por Hirsch como o estudo dó movimento da contradição capital/trabalho e da contradição entre os capitais individuais - seja a um nível teórico abstrato ou a um nível mais concreto - conduz a uma única conclusão: a tendência ao desmoronamento do capital. 
Destes aspectos deduz as funções do Estado, funções que definem o Estado e impedem a catástrofe para o capital. "A função fundamental do Estado é a garantia das condições gerais e externas ao processo de reprodução e das relações capitalistas, enquanto estrutura complexa, e, inclusive, das condições gerais de produção que não podem, fundamentalmente, ser produzidas pelos capitais individuais (p.62)" :

Entretanto, ele precisa que, "mesmo supondo um desenrolar do capital sem entraves, subsiste, ainda, a necessidade de garantir socialmente as condições fundamentais de sua auto-reprodução (...) :O que significa, antes de tudo, a salvaguarda da propriedade privada e a observância das regras da troca, difusão das regras formais homogêneas da concorrência, proteção e segurança do capital no exterior, garantia da disponibilidade do trabalho assalariado livre em condições lucrativas para o capital, assim como a criação das condições infra-estruturais para a produção (...) isto, na medida em que os capitais individuais não possam produzi-los por si mesmos (p.64)" :

Da dedução das funções do Estado ele deduz a forma Estado que se situa "como um aparelho externo de dominação e administração, da mesma maneira face aos capitalistas individuais ou face ao proletariado (p.64)" . E, "o Estado não pode apresentar-se a priori como defensor dos interesses dos capitais individuais, mas, ao contrário, deve assegurar a manutenção do processo de reprodução capitalista em seu conjunto, assim como a salvaguarda de toda a formação social como um sistema sócio-econômico complexo. Neste sentido específico, é uma máquina essencialmente capitalista, o Estado dos capitalistas, o capitalista coletivo em idéia ( $p .65$, grifado pelo autor)" :

Em resumo, o procedimento de Hirsch segue os seguintes pontos:

10:- a análise da reprodução social baseada na produção capitalista, na qual a lei da tendência à queda na taxa de lucro exprime o aspecto fundamental da dinâmica das contradições sociais; $2^{\circ}$ :- os estudo desta lei leva-o à conclusão na qual a dinâmica imposta pela mesma empurra o capitalismo à catástrofe; 3. - a análise das contra-tendências, pelo "desdobramento concreto do processo de acumulação, ou seja, as barreiras e possibilidade atuais face às quais se encontra o capital não são suficientes para responder porque "esta catástrofe não ocorreu até hoje" :Estas contra-tendências, por seu caráter contraditório, não explicam a manutenção da reprodução do capital; 
4. - das contradições às quais se chocam o capital, Hirsch deduz as funções do Estado;

5. - estas definem a forma Estado como o "capitalista coletivo em idéia";

$6^{\mathrm{O}}$ :- ele nota, rapidamente, que não é necessário utilizar a tese catastrofista para a dedução do Estado.

\section{Pierre Salama}

O último texto examinado é o de Salama :Sua dedução compreende do is pontos: o fetichismo da mercadoria e a dedução, propriamente dita, do Estado do capital. Além disso, propõe uma distinção metodológica entre o Estado e o regime político; este aqui como sendo a forma fenomenal do Estado.

A generalização das trocas mercantis implica na generalização das mercadorias e um fetichismo correspondente nas relações sociais. "As relações entre os homens na produção se revestem assim, num certo estágio de desenvolvimento, de forma duplamente enigmática. Elas aparecem por um lado como relações entre coisas (mercadorias) e por outro lado como relações de vontade entre unidades independentes umas em relação às outras, iguais entre si: como relações entre sujeitos jurídicos (Pasukanis, citado por Salama, p.123)" :E, "o resultado principal da teoria do fetichismo não é (portanto) o de que a Economia Política dissimula por trás das categorias materiais relações de produção que se estabelecem entre os homens, é o de que numa economia mercantil capitalista essas relações de produção adquirem necessariamente uma forma material e só podem existir nesta forma (Rubin, cit. por Salama, p.123)" :Enfim, cita Mandel afirmando que: "a permanência e a aceitação das relações mercantis é interiorizada na imensa maioria dos "cioiadãos livres" (...) E a força superestrutural principal do poder politico da burgūesia (...) A interiorização das relações mercantis corresponde portanto uma interiorização da democracia puramente formal (cit. por Salama, p.123)" :

Assim, a análise ao nível das trocas não permite a dedução da "necessidade tanto lógica como histórica do Estado (p.123)" "Em outros termos, pode-se compreender o Estado como algo que está ao lado e no exterior da sociedade, mas não se vê, fundamentalmente, a sua razão de ser (p.124)" .

O segundo ponto, a dedução do Estado do capital, compreende a análise das relações que se estabelecem entre o Estado e o capital. Estas não são relações de exterioridade; são relações orgâni- 
cas. Considerar a relação Estado/capital como relação de exterioridade significa considerar que o Estado se situa acima da lei do valor; "dai decorre uma concepção tecnicista $e$ instrumental (p 1:26)". E necessário "considerar que o que concerne ao Estado faz parte das relações sociais de produção (...) que essas mesmas relações exprimem laços orgânicos entre o Estado e o capital $(p .127)^{\prime \prime}$.

Salama procede à dedução segundo dois pontos: a) o Estado é um "elemento necessário à reprodução da relação de exploração"; b) o Estado é um "elemento regenerador dos capitais individuais". O ponto de partida desta distinção é a retomada por Rosdolski dos conceitos de capital em geral e capitais individuais ou capitais múltiplos. Estes conceitos se situam a níveis diferentes de abstração e permitem a Salama "considerar como ponto de partida a contradição entre o capital e o trabalho, e, em seguida, as contradições dos capitais múltiplos entre si na sua relação com o trabalho (p.127)" :

A reprodução do capital como relação social implica não somente na reprodução da burguesia e do proletariado, mas, também no intercâmbio entre estas classes: uma possuidora da mercadoria força-de-trabalho e a outra, compradora desta mercadoria. E sobre esta troca que se fundamenta a reprodução do capital. Mais ainda; a reprodução social neste processo apresenta duas faces: uma, aparente, clara, a troca de equivalentes; e a outra, escondida por esta aparência, a troca desigual, a exploração. Este processo é apresentado por Salama (aqui ele retoma Wirth) como a "contradição entre a liberdade formal do trabalhador enquanto proprietário de mercadoria e a sua não-liberdade enquanto produtor de mais-valia (Wirth, cit. por Salama, p.128)" : Esta contradição "tende a se resolver por si mesma": seja pela supressão da relação capitalista; seja pela sujeição total de uma parte dos trabalhadores. A reprodução desta contradição não é possivel sem o concurso do Estado. Assim "o Estado garante esta troca de equivalentes que, sem ele, não poderia perdurar. Garantindo o respeito das regras da troca, ele passa a ser quem garante a troca desigual (p.128, grifado pelo autor)" :

Entretanto, este processo aparece na realidade por seu lado fetichizado, a troca de equivalentes; e a solução da contracilição, como foi enunciada acima, não é possível se seu lado esconcicio não emerge ao nível das aparências, mostrando a exploração. Se para Wirth a solução da contradição é quase automática, sem o Estado, Salama a contesta demonstrando que pelo fetichismo da 
mercadoria a relação de exploração encontra-se escondida e só se desvenda em momento de crise.

Assim, introduz um novo dado para demonstrar a desfetichização da troca de equivalentes. Este novo dado é a crise que " por um lado é necessária à reprodução do capital, e por outro (...) reforça a contestação da relação de exploração pelas forças de oposição que ela segrega e nutre. Nesse sentido, ela atua como um desfetichizador objetivo (p.129, grifado pelo autor)" :Mas, se a crise "revela a uma parte mais ou menos importante dos trabalhadores o segredo da mais-valia (...) a conscientização mais ou menos elevada da relação de exploração que permite a crise e seu grau ou intensidade não implica, ou implica pouco, que se revele a natureza real do Estado (p.129)".

Entretanto, como contradição, dever-se-ia, também, considerar a solução por outra alternativa. Esta, a sujeição dos trabaIhadores pela burguesia, não é discutida nem por Salama, nem por Wirth. Hipoteticamente, poder-se-ia supor uma solução teórica à questão, pois esta al ternativa representaria um retrocesso histórico. Explicando melhor: a não-liberdade formal e real do trabalhador, exprime a supressão da relação salarial. Esta supressão considerada como submissão total do trabalhador, poderia ser representada pela relação servil ou escravista, formas sociais historicamente ultrapassadas pelo trabalho assalariado. No limite, esta al ternativa poderia representar, também, o fim do capital ismo sem que possamos dizer "a priori "qual seria a nova forma de organização social que o substituiria.

O segundo ponto da dedução constitui a análise da reprodução a nível dos capitais múltiplos. O aspecto essencial de diferen. ciação entre o capital em geral e os capitais múltiplos é a concorrência. No que diz respeito à dinâmica do capital, a concorrência atua no sentido de estabelecer uma tendência à perequação da taxa de lucro. Salama distingue dois niveis para a compreensão desta tendência: um nível abstrato, no qual "a perequação das taxas de lucro exprime a metamorfose dos valores em preço de produção $e$ traduz transferências de mais-valia"; e um nivel concreto, no qual "o movimento do capital (...) necessita um diferencial das taxas de de lucro ( $p$ 131)". Mas é necessário sublinhar que "a perequação das taxas de lucro não é um dado. E um resultado constantemente questionado (p. 131)": Além disso é necessário compreen. der, em primeiro lugar, que a perequação funciona como uma sanção social; como meio, através do qual, o mercado "orienta" a produção e o movimento dos capitais. Em segundo, a tendên- 
cia concreta do movimento dos capitais, dos ramos com baixa composição orgânica do capital para os ramos de composição mais elevada.

Se, num sentido mais geral (abstrato), a perequação da taxa de lucro representa sanção social, num sentido mais coṇcreto, a intervenção do Estado funciona no sentido de acentuar as transferências de mais-valia dos "setores retardatários para os setores de vanguarda". Isto explica porque a cinâmica da acumulação se caracteriza pelo fluxo de capitais em direção aos ramos e setores com composição orgânica crescente. O efeito obtido pela intervenção estatal por meio da transferência de mais-valia "pode ser comparado com o que se obtém através da crise. Ela deprecia certas frações de, capital em benefício de outras; por exemplo, desvia a concorrência em benefício de certos capitais. Acentuando a transferência da mais-valia social, fornece o meio pelo qual a reprodução do capital pode se efetuar da melhor maneira possivel. Pode-se portanto considerar que a intervenção do Estado pode desempenhar o papel provisório de crise (p 1:32, grifado pelo autor)".

Além de ser o modo normal de vida do capital, a crise "assinala o esgotamento das forças - consideradas em conjunto - que contrariam a baixa tendencial da taxa de lucro (p.133)". Assim, Salama considera que "a crise é necessária para o capital. Ela é o meio pelo qual o capital modifica as condições de exploração" A crise permite "ao capital que se regenere $(p .133)$ " Sem levar esta análise, da crise e seus efeitos sobre a reprodução do capital, a seu limite, Salama deixa implícita a idéia de Hirsch, na qual a dinâmica do capital em si mesma, tende à derrocada. Antes de atingir este ponto, afirma que "abandonado a si mesmo, o capital não poderia se reproduzir. O Estado é necessário; da mesma forma é necessário que o aparelho de dominação estatal não se constitua como aparelho privado da classe dominante. Esta intervenção do Estado é nećessária para pensar a crise. O Estado deve intervir na crise, a fim de limitar os efeitos destruidores para certas frações cio capital e, sobretudo, inversamente os efeitos de recuperação para essas mesmas frações (p.134)"':

A ação do Estado em relação à dinâmica do capital, situa-se, segundo Salama, sobre o movimento da taxa de lucro: modificando a tendência à perequação; e, sobretudo, a tendência à queda na taxa de lucro. A primeira modalidade de intervenção redistribui a mais-valia social, estruturando e hierarquizando a taxa de lucro em benefício dos setores de vanguarda, A segunda modalidade joga o papel da crise, permitindo uma regeneração do capital. 
Resumindo o procedimento de Salama, podemos dizer que sua dedução refere-se a dois pontos: 1 ? - a reprodução do capital em geral; $2^{\mathrm{O}}:-$ a reprodiução dos capitais múltiplos.

A reprodução do capital em geral, implica na reprodução do capital e do trabalho e, exige a troca entre os proprietários destes meios de produção. Esta troca gera u ma contradição entre a liberdade formal e a não-liberdade real do trabalhador. Contradição que tende a se resolver por si mesma. A solução desta contradição implica na supressão da relação capital/trabalho; portanto, esta relação só subsiste através da intervenção do Estado.

O segundo ponto é analisado de modo menos preciso e deixa implícitas suas conclusões. A tendência à perequação da taxa ce lucro não é um dado, mas um "resultado constantemente questionado"; não exige em si mesma, a intervenção do Estado. A análise lógica e teórica desta lei, independentemente da ação do Estado, apresenta resultados pouco coerentes com a realidade. A observação histórica, concreta, da ação desta lei permite que a tendência atual não é a homogeneização da taxa de lucro, mas uma hierarquização de taxas. Mais ainda, não permite explicar o movimento dos capitais dos ramos de baixa composição para aqueles de composição mais elevadas ${ }^{(9)}$. Assim, o que vai exigir a intervenção do Estado é a explicação do movimento concreto da acumulação que apresenta historicamente e "ex-post" uma hierarquia nas taxas de lucro. Salama considera que a explicação de Mattick é insuficiente. Este explica a hierarquização pelo movimento do mercado, quer dizer, pela oferta e demanda. Para Salama, o movimento da taxa de lucro não pode ser explicado sem considerar a ação do Estarło.

No que diz respeito à lei da tendência à queda na taxa de lucro, ela pode ser considerada como uma lei que regula a dinâmica do capital, cujos pontos críticos provocam a crise. Esta crise, gerida pelo Estado, vai permitir a regeneração do capital. Fica impl ícito que, sem a ação do Estado, a reprodução do capital torna-se impossivet.

\section{III - ALGUMAS OBSERVAÇÕES CRITICAS}

O estudo destes autores permite ${ }_{a}$ agora, resumir o procedimento geral da derivação. Para tanto, concentramo-nos sobre o procedimento teórico da derivação (dedução) do Estado do capital e deixamos de lado as imblicacões e os resultados desta derivação. Chamamos atenção para o fato de que, com este procedi- 
mento, perde se muito das nuances e das diferentes contribuições de cada trabalho na medida em que são reduzidos a um denominador comum.

Em todos os textos estudados, podemos afirmar: a análise baseia-se no estudo das contradições do capital considerado em si mesmo, independentemente do Estado. A análise destas contradições leva a cada um dos autores a concluir, implícita ou explicitamente, que o Estado é necessário ao capital. E isto vai de um extremo - a tese catastrofista em Hirsch - a outro. O Estado como garantia da reprodução da relaç̃̃o capital/trabalho, através das relações jurídicas, em Wirth.

A análise mais aprofundada destas contradições exige que o Estado seja um aparetho separado do capital; que tome forma impessoal ao lado e acima da sociedade. Somente sob esta forma, o Estado pode preencher as funções exigidas para a reprodução do capital.

Enfim, a definıção destas funções em relação à reprodução do capital, permite a qualificação do Estado. O Estado como "capitalista coletivo em idéia". é capitalista porque preenche funções visando à reprodução do capișal. O Estado "como instrumento de dominação de uma classe sobre a outra, não é específico ao capitalismo" $(10)$ afirma Wirth (p.115) :O Estado específico ao ca pitalismo é aqule que serve de "meio para manter a dominação do capital sobre a sociedade (Wirths, p.119)" 'A dominação do capital sobre a sociedade só é possível por sua reprodução ampliada, apoiada pelo Estado que preenche determinadas condições necessárias, sem as quais esta reprodução torna-se impossível.

Visto desta maneira, a dedução do Estado do capital coloca certos problemas: primeiro, a relação Estado/capital é proposta como relação orgânica, desde seu ponto de partida. Esta relação não sendo demonstrada em nenhum trabalho, termina por se apresentar como postulado de que podemos mesmo prescindir. Isto nos leva a uma relação de exterioridade, o que não parece ser a intenção dos autores. O segundo ponto diz respeito à dedução propriamente dita. Ela não é claramente explicitada em nenhum dos trabalhos. Desta maneira, acaba-se por confundir a dedução do Estado com a dedução da necessidade da intervenção do Estado. O último ponto refere-se à forma Estado. Esta é muito pouco trabalhada e não permite formar uma idéia precisa do que é que constitui esta forma e, quais são as relações com seu conteúdo. Vamos examinar, em seguida, cada um destes pontos. 


\section{A relação orgânica Estado/capital}

Todos os textos estudados propõem que a relação Estado/capital não é uma relação de exterioridade, mas uma relação orgânica. Mas, nenhum dos trabalhos explicita claramente a organicidade desta relação. Poderíamos, então, supor que a demonstração da necessidade do Estado, o desdobramento de suas funções face ao capital constituiriam, ao mesmo tempo, a demonstração da organicidade daquela relação. Nós consideramos, entretanto, que esta suposição é falsa. Se a reprodução do capital exige a existência de uma instituição formalmente ao lado e acima do capital, isto não implica, necessariamente, que esta instituição seja realmente ligada organicamente ao capital. Além disso, seguindo passo a passo cada uma das diferentes demonstrações, a relação Estado/capital se estabelece a partir das funções preenchidas pelo Estado face ao capital. Se consideramos que essa relação é orgânica, as funções deveriam resultar dessa relação e, não, o contrário. Enfim, a definição de Estado, após a demonstração de sua necessidade, a partir de suas funções, permite toda sorte de ambigüidades e malentendidos. Por exemplo: uma crítica de que esta análise seja funcionalista ${ }^{(11)}$.

E preciso, portanto, colocar "a priori" ou demonstrar a questão da relação orgânica Estado/capital; em seguida, definir, precisamente, a noção de FORMA ESTADO; enfim, considerar que o que se deduz não é mais o Estado, mas, a necessidade de sua intervenção.

Os dois primeiros pontos não são exatamente separados. $A$ definição "a priori" do Estado, implica diretamente em sua relação com o capital. Várias definições são possiveis (ou não propostas) mas rós não as discutiremos aqui (12). Tomamos como ponto de partida a noção avançada por Salama de Estado como abstração. Esta noc̣ão abstrata está compreendida, é imanente à noção abstrata de capital como relação social. Isto fica claramente colocado por Lefebvre quando diz que ". . . cada vez que um "agente" ou "ator" tem qualquer relação, normal ou conflitiva, com outro "agente", indivíduo ou grupo, o Estado está lá, terceiro incluído. Mais que testemunha: ele mesmo um agente. Já está presente como conservador e fiador dos contratos. A espada de Dâmocles estatal, como diz a figura clássica da linguagem, suspensa sobre todo ato social como uma ameaça de sanç̃o (De L'Etat, t.3: p.201)". Esta mesma proposição aparece em Pasukanis em sua análise da gênese histórica do Estado capitalista. "Todo aperfeiçoamento posterior 
do Estado burguês (. . . ) pode ser reconduzido ao princípio segundo o qual nenhum dos dois agentes no mercado, pode regulamentar a relação de troca por sua própria autoridade; esta aqui exige, ao contrário, terceira parte que encarne a garantia recíproca que os possuidores de mercadorias se concedem mutuamente em sua qualidade de possuidores de mercadorias. . (p.136)" .

Neste aspecto, considera-se o Estado e o capital ao mesmo nível de abstração. Não podemos "separá-los" um do outro; o capital como relação social não existe, e não pode existir sem o Estado. Logicamente não se pode conceber o capital como relação social de exploração que se estabelece entre indivíduos "livres e iguais", se não se considera a relação de dominação implícita a esta relação. Historicamente, a constituição desta relação, sua gênese e consolidação, não pode ser concebida sem o concurso de uma instituição que garanta esta relação.

É a este nível que a relação Estado/capital é orgânica. Neste mesmo nível a relação Capital/trabalho (ou burguesia/proletariado é orgânica. A passagem a um nível mais concreto implica na "separação" entre o Estado e o capital; implica, também, na separação entre capital e trabalho. Estes se materializam nas classes fundamentais da sociedade capitalista; o Estado se materializa num aparelho estatal.

\section{A dedução do Estado ou a necessidade da intervenção estatal?}

Se concebemos a relação orgânica entre Estado e capital, como vimos acima, podemos afirmar que aquilo que os autores dos trabalhos examinados deduzem não é precisamente o Estado, pois como noção abstrata, ele é imanente ao capital. O que é deduzido é muito mais a ação do Estado, materializada num aparelho estatal; é a intervenção do Estado face às contradições da reprodução do capital. Vejamos com mais detalhes.

Como já observamos, em todos os trabalhos examinados, não existe, explicitamente, fundamentação sobre a relação orgânica Estado/capital. Toda análise gira em torno do conceito de necessidade. Este conceito exige, do ponto de vista puramente lógico, que a justificação da existência e da ação do Estado fundamente-se na reprodução do capital. A análise desta, através de suas leis, justifica, assim, o Estado. Mas, esta justificativa é possível, se, e somente se, a análise do funcionamento do capital levar à conclusão da impossibilidade de existência dele sem o concurso do Esta- 
do. Em outros termos, como exprime claramente Hirsch, o Estado é necessário para evitar a derrocada do capital. Encontramos aqui os traços do economicismo e um determinismo um tanto ou quanto exagerados. A busca de uma justificativa para a existência do Estado, leva, principalmente Hirsch, a exagerar certas contradições. Se O Estado e o capital mantêm entre si relações orgânicas, não é necessário demonstrar sua necessidade. Este procedimento traz, em si, o risco de considerar a dinâmica do capital em si mesma, independentemente do Estado, e introduz-se o Estado somente como recurso ao capital. Assim, Estado a capital acabam por se apresentarem como relações de exterioridade.

Este tipo de análise retoma, de certo modo, aproximadamente, a mesma argumentação das teorias catastrofistas devidas, ao menos em parte, às análises de Rosa Luxemburgo. Substitui-se, neste caso, o "ambiente social não capitalista" pelo Estado, se bem que cada um joga papel diferente em cada teoria.

Podemos supor, entretanto, que os estudos examinados colocam a necessidade da intervenção do Estado e não a necessidade do Estado, tomando como dada a relação orgânica Estado/capital (o que não é claramente explicitado). Neste caso, descartamos as teses catastrofistas, mas eliminamos a dedução do Estado em benefício da dedução da intervenção do Estado.

A demonstração da relação orgânica entre Estado e capital deveria constituir a base da dedução e permitir a definição das funções gerais do Estado capitalista. Em seguida, a análise lógica e histórica da reprodução do capital, a constatação e a definição das restrições econtradas por esta reprodução, deveriam permitir a dedução das tarefas historicamente definidas do Estado.

Não podemos supor, a partir da análise das leis gerais que regulam a dinâmica da reprodução do capital, que este seja débil, que tende à estagnação, como o faz crer Hirsch várias vezes. Podemos, no entanto, a firmar que a reprodução do capital é contraditória; que encontra historicamente várias barreiras. Mas estas têm sido superadas ao longo da história com ou sem a intervenção do Estado, conforme as condições específicas de cada caso. Podemos, igualmente, afirmar que na fase contemporânea do capitalismo, as barreiras encontradas pela reprodução do capital não podem ser superadas sem o auxílio do Estado. Mas, isto não significa, de forma alguma, fraqueza do capital ou qualquer tendência à estagnação. 


\section{A forma Estado.}

A teoria da derivação constitui reação aos excessos da teoria do Estado fundadas em seu conteúdo de classe. Esta reação deveria apresentar uma teoria do Estado, a partir da categoria forma. No entanto, a forma Estado "em realidade é muito ligeiramente abordada $(13)$ "'. Na maior parte dos trabalhos, esta questão é apenas esboçada ou fica muito mais implícita do que explícita, sem uma teorização mais precisa. Por ou tro lado, a questão da natureza do Estado e sua relação à forma não é igualmente contemplada nestes textos.

Este último aspecto pode levar a duas posições extremas, igualmente insatisfatórias, segundo acreditamos. A primeira posição subordina a forma Estado à forma capital; esta aqui sendo o sujeito e aquela lá o objeto cujo movimento seguiria como sombra o movimento do capital; a segunda, seria a autonomia da forma Estado; este constituiria, também, um sujeito equivalente ao capital, com seu próprio movimento.

No limite, a primeira concepção permite: seja a retomada da tese instrumentalista (o Estado como instrumento do capital e não de uma classe); seja, uma redução do Estado ao capital. A este respeito, citamos Sanchez que escreve: ". . . apesar da oposição entre a teoria de Negri e de Altvater, eles têm um ponto fundamental em comum: tanto em um quanto em outro, o capital é sempre o verdadeiro e único sujeito do processo. Em Negri, o Estado torna-se o capital, em Altvater o Estado não existe, a não ser em função do capital. A especificidade e a realidade do Estado dissolvem-se no capital (14)"."

Segundo sabemos, é o próprio Sanchez que leva ao limite a outra opção. Ele afirma que "A tensão Marx-Hegel implica em conceber o Estado como uma forma que terá seu estatuto próprio, enquanto forma em movimento, similar ao conceito de capital; isto implica que a sociedade moderna é dominada por duas potências: o Estado e o capital (15)"'.

Estas duas abordagens apresentam como inconveniente principal a impossibilidade de incorporar a luta de classes na análise da forma Estado.

Uma tentativa intermediária é apresentada por Salama. A partir de um corte conceitual entre forma do Estado e forma Estado e da distinção metodológica entre abstração real e manifestação concreta, propõe a "separação" entre Estado e regime político (16) A forma Estado é deduzida do ciclo do capital; a sucessão de ca- 
tegoria M - V - D - C (Mercadoria - Valor - Dinheiro - Capital) implica o Estado. Este, como uma abstração real, situa-se como forma "ao lado e acima do capital" . Esta forma ". . se efetiva na realidade da luta de classes sob a forma do regime político (Salama, 1980: p. 135)". Esta é a forma do Estado.

Embora esta abordagem nos permita avançar no estudo da forma Estado, não nos permite, ainda, avançar na questão da relação forma/conteúdo do Estado capitalista. Este é um ponto ainda não suficientemente desenvolvido na teoria do Estado.

\section{IV - AS FUNCOOES DO ESTADO: Intervenção Estatal $\boldsymbol{e}$ Intervenção Pública.}

A teoria da derivação, colocando em evidência a questão da forma Estado, permitiu o avanço bastante rápido na análise dos problemas relacionados às relações Estado/capital. Ao mesmo tempo permitiu o estudo mais sistemático das funções que o Estado cumpre face ao capital.

Nesta seção de nosso trabalho, tentaremos explicitar melhor certos conceitos que nos permitirão partir da análise abstrata e, chegar ao estudo concreto da ação estatal.

Neste sentido discutiremos sucessivamente os seguintes pontos: as relações Estado/Capital ou as funções do Estado; a intervenção estatal e a intervenção pública.

\section{As funções do Estado}

Nosso ponto de partida consiste na consideração de que a relação Estado/capital é orgânica. Isto ao nível mais geral e abstrato; contudo não menos real. A passagem do abstrato ao concreto corresponde à introdução de novas determinações aos conceitos já examinados. Por um lado, já examinamos as relações entre os conceitos de Estado e o de regime político; por outro, vamos examinar e relacionar a passagem do conceito de capital ao de sociedade. Mais especificamente, da reprodução do capital à reprodução da sociedade.

A sociedade capitalista moderna - isto é, aquela dominada pelo modo de produção capitalista - não é homogênea. Cada sociedade está profundamente marcada por sua herança histórica e pelas relações de força que se estabelecem dinamicamente em seu interior e exterior. Assim, os conceitos de regime político, intervenção estatal, intervenção pública, etc, tomam diferentes formas 
segundo a realidade concreta que se leve em conta.

A análise da reprodução do capital ao nível abstrato, considera fundamentalmente as contradições inerentes ao modo de produção capitalista. Mas estas estão imersas no quadro complexo de uma sociedade historicamente determinada. Sem a pretensão de desenvolver um estudo histórico (pois este não é o objeto deste trabalho) queremos esboçar os traços principais que nos permitam avançar nesta direção.

Em princípio, queremos realçar a distinção entre relações sociais e relações sociais de produção. Consideramos que em se tratando do modo de produção, estes dois conceitos devem se confundir; mas, a nível mais concreto, o conjunto de relações sociais que regulam a reprodução da sociedade é mais amplo do que o das relações sociais de produção, conquanto estejam estreitamente vinculados um ao outro. Por exemplo: a reprodução da família (17) apesar de determinada pelas relações capitalistas de produção, ocorre sob relações espec íficas "fora" das relações de produção. A reprodução do capital implica na reprodução da sociedade e vice-versa. A ação do Estado, visando à reprodução do capital, requer a intervenção sobre o conjunto da sociedade. É desnecessário dizer que a reprodução do capital e da sociedade reproduz automaticamente, o Estado.

A representação da ação do Estado (de maneira mais sistemática) e apresentada através das "funções" de acumulação e legitimação (18). Elas não são exclusivas nem, necessariamente, contraditórias.

Mesmo que se possa quantificá-las, a matematização destas funções significa uma redução que pode levar a interpretação incorretas da realidade. Isto, porque, se interpenetram e, a mesma ação do Estado, pode apresentar as duas funções ao mesmo tempo. Mas pode-se afirmar, "a priori" que a função/acumulação é determinada fundamentalmente, pelas restrições à acumulação, enquanto a função/legitimação o é pela reprodução social. A for mulação de Salama, sobre este ponto, é bastante precisa: a função/ acumulação concerne ao Estado e a função/legitimação, ao regime político (19). A ligação entre estas funções, situadas em níveis diferentes de abstração, representa a "metamorfose" do abstrato ao concreto. 


\section{A Intervenção Estatal e a Intervenção Pública}

A expressão "intervenção" (ou intervencionismo) exprime a idéia de separação entre "a sociedade, sua estrutura econômica e o Estado", observa Altvater (20). Este conceito remete-nos, por um lado, a concepção de estado ao exterior do capital; por outro, a concretização destas categorias, corresponde a separação entre o Estado e o Capital. Em outros termos, existe um processo de "autonomização" do Estado (21) . É precisamente esta autonomização que permite a utilização deste conceito, especificando-o e, preenchendo-o de determinações concretas.

A relação orgânica Estado/Capital, definida ao plano abstrato, transforma-se em separação; é rearticulada através do conceito de intervenção. O intervencionismo estatal corresponde, então, às realizações das possibilidades definidas pelas funções. Estas exprimem o conjunto de possibilidades e necessidades de ambas as partes; isto é, do Estado e do capital. A intervenção exprime, portanto, suas realizações parciais ou integrais. Sob este aspecto, podemos distinguir, também, dois níveis de intervenção: a estatal e a pública ${ }^{(22)}$. A primeira, situa-se num plano de determinação mais geral, abstrato; a segunda, a nível mais complexo das determinações concretas. Sob este ponto de vista, existe correspondência entre as funções e a intervenção do Estado.

Esta distinção permite Salama definir certos limites à intervenção do Estado. Estes, são determinados no plano abstrato pelas restrições e necessidades da acumulação do capital, cuja dinâmica depende fundamentalmente de três fatores: - o diferencial das taxas de lucro; - a lei da baixa tendencial da taxa de lucro; e o nivel atingido pelas forças produtivas (23). Estes pontos definem um eixo em torno do qual varia a intervenção pública, "“forma de existência da intervenção estatal".

Por seu lado, a intervenção pública depende - ela também _ "de três fatores: o regime de acumulação dominante; o estado e a evolução prevista da luta de classes e de suas frações; expressão 'dessas lutas a nível político ${ }^{(24) " \text {. }}$

O conceito de intervenção pública deverá permitir-nos a passagem do estudo teórico à interpretação da realidade concreta $^{(25)}$. Mas, é necessário enriquecê-lo um pouco mais. Da maneira como o estudamos parece-nos restritivo. Os fatores acima citados, - determinantes da intervenção pública - podem ser entendidos como o núcleo dominante da sociedade capitalista. 
O regime de acumulação exprime a dinâmica concreta da rede complexa de circulação do capital, estruturada, hierarquizada e historicamente definida. Os dois outros fatores representam os aspectos objetivos e subjetivos da estruturação social em torno do capital.

As sociedades constituem-se (além deste núcleo central) de outros elementos como: o da família, o chamado setor informal, o campesinato etc. Estes elementos articulam-se através de uma rede de relações sociais em torno das relações de produção capitalista. Assim, "o estado e a evolução prevista da luta de classes" não se exprime de forma linear e automática a nível das relações políticas. Por outro lado, a pressão das forças sociais, através das relações políticas não se transforma, automaticamente, em medida de política econômica.

Além disso, a passagem da luta de classes para sua expressão no político, depende das instituições existentes, que nem sempre permitem a expressão dos interesses do conjunto das classes sociais . Em regimes de tipo autoritário, apenas as classes ou frações das classes dominantes podem se exprimir, enquanto que as demais são duramente reprimidas. Nos regimes liberais, a realidade demonstra que o que ocorre corretamente é a expressão das coalisões e das alianças que aparecem a este nível.

Enfim, a passagem da relação entre as forças políticas e a intervenção pública efetiva, deverá atravessar a estrutura política, técnica e administrativo-burocrática que filtra as aspirações expressas e as devolvem sob forma de políticas econômicas. Mais ainda; esta última forma apresenta-se como discurso técnico, atrás do qual se escondem os determinantes fundamentais da intervenção pública, além de divulgarem a ideologia do interesse nacional.

Finalmente, é preciso observar que não consideramos, no conceito de intervenção pública, as regulamentações e arbitragens realizadas pelo Estado, visando à reprodução da totalidade social.

\section{$V$ - CONCLUSĀO}

Nós estudamos neste trabalho a teoria do Estado segundo a escola da derivação. Assim, discutimos, sucessivamente, o procedimento de derivação, a relação Estado/capital, a forma Estado, os níveis de abstração e a passagem do Estado ao regime político. Discutimos, igualmente, a sistematização das funções do Estado, sua transformação em intervenção estatal e pública. Finalmente, trabalhamos o conceito de intervenção pública de forma a torná- 
lo capaz de apreender a realidade concreta.

A título de conclusão, faremos algumas observações sobre esta teoria e sua aplicação como meio de análise e interpretação da realidade.

A teoria de derivação foi desenvolvida, visando esclarecer às relações Estado/capital nas sociedades capitalistas desenvolvidas. Assim, sua utilização para o estudo de países subdesenvolvidos, pode aparecer um pouco duvidosa.

Salama (26) afirma que não podemos "deduzir o Estado e sua natureza nos países "subdesenvolvidos" utilizando os avanços da escola da derivação". Isto, pelas seguintes razões: a) "o modo de produção capitalista não é o produto das contradições internas a estas sociedades (p.29); b) "a difusão das relações mercantis é incompleta e específica (p.30)". Desta forma, propõe que "a natureza dos Estados da periferia é conferida pelas relações que estes últimos devem estabelecer com os Estados-Nações do Centro (p.40)".

A dedução lógica da forma Estado é realizada a nível geral e abstrato. Não é ligada a qualquer formação social em particular. Enquanto teoria, refere-se ao modo de produção capitalista. A gênese histórica e espacial deste modo de produção articula-se em torno da formação dos Estados-Nações, profundarnente diferenciados entre si. Assim, mesmo para os países do "Centro", a utilização da teoria da derivação exige que se leve em conta a evolução do modo de produção capitalista até a sua dominação completa e o ritmo da cifífusão das relações mercantis em cada realidade específica. O processo histórico deverá preencher de determinações concretas os conceitos de regime político, funções do Estado e intervenção estatal e pública.

No caso da "Periferia" ou dos países "subdesenvolvidos", devemos ter em conta o fato de que "o modo de produção capitalista não é o produto das contradições internas a estas sociedade", que cai de "pára-quedas do exterior", na expressão de Salama. Que a difusão das relações mercantis ocorre muito mais tarde, mas num ritmo muito mais acelerado.

Assim, o Estado nos países subdesenvolvidos é capitalista, cuja forma é a de um "capitalista coletivo em idéia"; sua natureza não é conferida diretamente pelo capital, mas mediada pelo sistema mundial (27). Sua forma fenomenal nem sempre é aquela das democracias burguesas, porém de ditaduras ou de certas formas de democracias muito mais restritivas. 


\section{NOTAS}

(1) Pulantzas (1981:p.14), apresenta uma crítica a estas idéias nos seguintes termos: "Chamemos as coisas pelo seu nome: não se deveria falar de natureza de classe, mas de utilização de classe do Estado. Eu relembrava a expressão "dupla natureza do Estado", mas ela não exprime a realidade destas análises: a verdadeira natureza do Estado, é o primeiro Estado; a outra, é um hábito. Como na teoria política secular, aquela do Estado meio-homem, meio animal: o verdadeiro Estado-poder, para ela também, não é a metade que está no lado do quintal (no lado das classes) mas o outro, que está do lado do jardim."

(2.) Uma resenha excelente destes trabalhos encontra-se em Holloway \&Picciotto (1980: p. 29-52).

(3) A maior parte do debate foi realizado em língua alemã, portanto a disponibilidade destes textos em outras línguas é um pouco limitada. Encontramos em francês uma coletânea organizada por Jean Marie Vincent (1975) e intitulada de “'L'Etat contemporain et le marxisme"; em inglês, organizada por Holloway \& Picciotto (1978) com o título "State and Capital"; em espanhol, organizada por Heinz Rudolf Sonntag e Héctor Valecillos (1982) com o título de "El Estado en el capitalismo contemporaneo"; em português publicou-se outra coletânea, mais restrita, sob o título "Estado e Capitalismo" de Claus Offe, Winfried Vogt e Jürgen Frank.

(4) Os trabalhos dos três primeiros autores foram estudados na coletânea organizada por Jean-Marie Vincent (1975) e, o último, em sua versão brasileira publicada no n? 26 dos Estudos Cebrap (1980).

(5) Romam Rosdolsky (1976: p.73-84) chama a atenção sobre a importância desta concepção em Marx e para a distinção entre o capital em geral e os capitais múltiplos.

(6) Estas atividades não rentáveis para os capitais individuais podem ser interpretadas de outro modo. O risco da abordagem realizada por Altvater é de confundir sua interpretação com aquela realizada pela economia burguesa. A necessidade do Estado segundo os autores neoclássicos aparece com a distinção entre bens públicos e bens privados. A mercadoria estudada segundo seu valor de uso é que permite esta distinção. Para Altvater existem bens ou serviços necessários à reprodução do capital em geral, cuja produção não é rentável para os capitais privados. Assim, este ângulo privilegia o aspecto útil da produção pública. 
(7) Aliás, segundo Salama, esta contradição não se soluciona. Considera justamente que ao nível das trocas, o processo de fetichização das mercadorias impede a solução desta contradição. É somente nos momentos de crise que surge como possibilidade, a solução desta contradição.

(8) Desenvolveu-se um importante debate em torno desta lei. Não faremos uma exposição deste debate, os interessados podem recorrer ao excelente artigo de Guido Mantega (1976); aos artigos de Cogoy, Sweezy e Matick reunidos no livro Teoria da acumulação capitalista (1977); a David Yaffe (1975); a Joseph Gillman (1980) e a Maurice Andreu (1980).

(9) Se consideramos que a análise teórica não pressupõe, necessari . amente, a diferenciação e hierarquização na taxa de lucro.

(10) Deve-se notar que, não é, também, um Estado Capitalista. Esta passagem exprime uma comparação que não é, necessariamente, justa.

(11) Ver, por exemplo, o artigo de José Luiz Soliz-Gonzales (1980).

(12) E necessário sublinhar que nós nos referimos não somente à forma Estado mas, também, ao seu conteúdo e à dinâmica das relações forma $x$ conteúdo.

(13) Jaime Sanchez-Susarrey (1982: p.13).

(14) idem, p.13

(15) idem, p.03. Ver também p. 77 onde afirma: “A luta de classes, para nós, não pode constituir nem o ponto de partida da análise da forma Estado nem da análise do regime político pelo fato de que ela não constitui um dado imediato e não problemático da sociedade moderna".

(16) idem, p.80. Ele propõe, ainda, outro nível: o governo. Diz que "existe, então, uma distinção a ser feita entre a forma Estado, o regime político e o governo: um regime político é, somente, o quadro através do qual a forma Estado adquire sua materialização no governo, o Estado, abstração concreta, existe como UniversalSingular no Governo".

(17) Ver Annie L.Cot e Bruno Lautier (1981). Podemos, igualmente, pensar ao menos parcialmente, nas atividades que Rosanvallon (1980) chama de economia subterrânea. Estas atividades permitem a definição daquelas que não seriam imediatamente mercantis, as quais, subordinadas e articuladas às relações capitalistas constituem uma parcela da totalidade social.

(18) A questão sobre as funções do Estado pode ser revista nos diversos artigos citados neste trabalho. Ela nos leva à uma lista de 
funções que podem ser reunidas muito bem nestas duas funções. O primeiro a sistematizá-las foi James O'Connor (1977). Para ele, estas duas funções situam-se ao mesmo nível e se excluem contraditoriamente. Para Salama, elas situam se a níveis diferentes de abstração e não são necessariamente contraditórias.

(19) Pierre Salama (1980: p.138 e seguintes)

(20) Elmar Altvater (1975: p.135)

(21) Sobre este ponto, veja por exemplo: Nicos Poulantzas (1975) e Jean-Marie Vincent (1979).

(22) Pierre Salama (1980: p.135)

(23) Idem, (1983: p.51)

(24) Idem, (1983: p.74)

(25) Idem, (1983: p. 51 e seguintes). Ele desenvolve este ponto considerando a intervencão no ciclo do capital e fora do ciclo. No ciclo, a intervenção constitue a "função de regeneração co capital', fora do ciclo, ela constitue a "função de gestão estatal da força de trabalho".

(26) idem, (1983: p.28)

(27) Idem, (1983: p.42)

\section{BIBLIOGRAFIA}

ALTVATER, Elmar. "Remarques sur quelques problèmes posés par I' interventionnisme étatique". In: VINCENT, Jean-Marie. $L^{\prime}$ Etat contemporain et le marxisme. Paris, C.E.P./ MASPERO, 1975.

ANDREU, Maurice. "Joseph Gilmann et l'attraction Keynésienne dans la crise du marxisme contemporain". In: GILMANN, Joseph M. Labaisse du taux de profit. Paris, E.D.I. 1980.

COGOY, Mário; SWEEZY, Paul e MATICK, Paul. Teoria da acumulação capitalista. Porto, PUBLICAC̣ÕES ESCORPIÃO, 1977.

GILLMAN, Joseph M. La baisse du taux de profit. Paris, E.D.I. 1980.

HIRSCH, Joaquim. 'Eléments pour une théorie matérialiste de L'Etat". In: VICENT, Jean-Marie. L'Etat contemporain et le marxisme. Paris C.E.P./MASPERO, 1975.

HOLLOWAY, Jonh e PICCIOTTO, Sol. "Etat et capital: le débat allemand sur la 'dérivation' de I'Etat". Paris,C.E.P./MASPERO 1980. Critiques de L'économei politique, nouvelle série, janvier-mars. 
L.COT, Annie e LAUTIER, Bruno. "La frontiére du capital. L'usine et la famille au-delà du miroir de la crie". NON! Repères pour le Socialisme. n. 9, septembre-octobre 1981.

LEFEBVRE, Henri. De L'Etat. Paris, U.G.E./10-18, 1974. 4 vol.

MANTEGA, Guido. "A lei da taxa de lucro: A tendência da quedé ou a queda da tendência?". In: Estudos CEBRAP, Editora Brasileira de Ciências Ltda. São Paulo, Abril-Maio-Junho 1976.

O'CONNOR, James . USA: A crise do Estado Capitalista. Rio de Janeiro, PAZ e TERRA, 1977.

PASUKANIS, Eugene. La théorie générale du droit et le marxisme. Paris, E.D.I., 1976.

POULANTZAS, Nicos. Hegemonia y domination en el Estado moderno. Cordoba, SIGLO XXI, Cuadernos de Pasado y Presente, 1975. 3ed.

POULANTZAS, Nicos. L'Etat, le pouvoir le socialisme. Paris, PUF/Quadrige, 1981. 2ed.

ROSANVALLON, Pierre. "Le développement de $I^{\prime}$ économie souterraine et l'avenir des sociétés industrielles". Paris, LA DOCUMENTATION FRANC̣AISE, 1980. Problémes économiques $n^{O}$. 1682. Paris, 16 juillet 1980.

ROSDOLSKY, Roman. La genése du "Capital" chez Karl MarX. Paris, C.E.P./MASPERO, 1976. t.l.

SALAMA, Pierre. "Estado e Capital. O Estado capitalista como abstração real". Estudos CEBRAP n. 26. São Paulo, 1980.

SALAMA, $P$

SALAMA, Pierre e MATIAS, Gilberto. O Estado superdesenvo/vido. São Paulo, BRASILIENSE, 1983.

SANCHEZ-SUSARREY, Jaime. La forme Etat et la forme Marchandise. (essai critique sur la théorie de la dérivation) Tese 3. ciclo, Paris, I.E.D.E.S. Paris I, 1982.

SOLiZ--GONZALEZ, José Luiz “La question de L'Etat dans les pays capitaliestes 'sous-developpés': quelques problémes de méthode". Paris, C.E.P./MASPERO, 1980. Critiques de l'économie politique $n^{O}$ 13, nouvelle série, octobre-décembre 1980.

SONNTAG, Heinz Rudolf e VA.LECILLOS, Hector. El Estado en el capitalismo contemporaneo. México, SIGLO XXI, 1982.

VINCENT, Jean-Marie. L'Etat contemporain et le marxisme.Paris, C.E.P./MASPERO, 1975. 
VINCENT, Jean-Marie. Les mensonges de L'Etat. Paris, LE SY. COMORE, 1979.

VOGT, Winfreid; FRANK, Jürgen e OFFE, Claus. Estado e Capitalismo. Rio de Janeiro, TEMPO BRASILEIRO, 1980.

WIRTH, Margareth. "Contribution à la critique de la théorie du capitalisme monopoliste d'Etat."' In: VICENT, Jean-Marie. $L^{\prime}$ Etat contemporain et le marxisme. Paris, C.E.P./MASPERO, 1975.

YAFFE, David S. "La theorie marxiste de la crise, du capital et de I'Etat.". In: VINCENT, Jean-Marie. L'Etat contemporain et le marxisme. Paris, C.E.P./MASPERO, 1975. 